\title{
A FIRST USABILITY STUDY OF INTERNOVA E-LEARNING PLATFORM AS A TECHNOLOGICAL RESOURCE FOR AGRI-FOOD BUSINESSES
}

\author{
Pedro Miguel Faria, Isabel Araújo, José Evaristo Lima, David Rodrigues and João Nuno Azevedo \\ Instituto Politécnico de Viana do Castelo, Viana do Castelo, Portugal
}

\begin{abstract}
With the development of the knowledge society and the growth of the increasingly competitive global economy, businesses face new challenges. In this context, the INTERNOVAMARKET-FOOD project arises with the general objective of contributing to the internationalization, technological innovation and marketing of companies of the agri-food sector in the Euro-Region of Northern Portugal and Spain. In this context, online training courses have been developed. This article presents a first usability study about the INTERNOVA E-Learning Platform. In order to analyze the online training, a questionnaire was applied to 4 volunteers, 2 acting as trainees and 2 as trainers. The questionnaire was applied after they used and executed some tasks requested in the platform. The results obtained suggest that the platform has a potential for good usability, is intuitive and dynamic.
\end{abstract}

\section{KEYWORDS}

LMS, Open edX, Usability, E-learning Digital Platform, Lifelong Learning, Training in Companies

\section{INTRODUCTION}

As the global economy grows, companies face new challenges. In this context, the INTERNOVAMARKET-FOOD project was born with the general objective of contributing to solid and sustainable businesses in the Euro-Region of Northern Portugal, with an optimum level of productivity, capable of generating a sufficient level of employment and having more and better companies that can sell products and services of higher quality, with higher added value, in the national and international market. For this purpose, the need for training in agri-food companies was detected. However, these are geographically dispersed and the time available for training is scarce. Therefore, the development of online training for companies was considered, having chosen to develop an e-learning platform, facilitating the access of workers from any place and at any time, as long as they have access to the Internet. This article introduces the e-learning in the context of the project, presents the INTERNOVA platform focused in its structure design and content production, followed by the description of an usability study and the results obtained.

\section{THE E-LEARNING CONTEXT IN THE PROJECT}

Driven by globalization, we live in a society that is increasingly competitive at a global level, also characterized by a network society (Moreno, 2015) and consequently the need for continuous training and permanent qualification throughout life (Alheit \& Dausien, 2006). It should be noted that in the last two decades there has been an evident growth in the need felt and/or personal interest in the search for personal qualification (Field, 2000), generally due to the acceleration of technological change and the rapid devaluation that affects professional knowledge. Training and qualification are no longer restricted to the "preparation" phase of active life but are a permanent factor in accompanying the professional journey (Alheit \& Dausien, 2006). In addition, organizations are currently required to invest and value their intellectual capital. It should be noted that the need for qualification of a company's employees fosters learning for the development of skills that should be recognized by the company itself, as well as by society itself. However, the availability of the target audience, 
active agents in the business world, to attend training sessions in person is limited, so online training is an alternative. In addition, the field of education has never been indifferent to new technologies and, eventually, to the opportunities offered by the Internet. Technology-supported learning encompasses, in principle, the use of digital technologies to support education. In this context, e-learning and online course development platform models assume a central role in continuous training in businesses (Barros \& Neves, 2017). These systems allow the creation of learning facilitator environments, generally providing means for the distribution of interactive multimedia content, while providing online communication channels and means of collaboration, in addition to the multiple functionalities associated with evaluation, both for training and summative purposes (McGill \& Klobas, 2009). These platforms make it possible to foster the learning process in a large number of people in a decentralised way (Balaouras et al, 2018).

\section{INTERNOVA E-LEARNING PLATFORM}

Instigated by today's constantly evolving world, whose competitiveness is increasing, the need arises for training throughout professional activity, including agri-food companies. However, the availability of active agents in the food business world is limited. Therefore, it was considered pertinent to provide training in e-learning format. In this context, it was considered adequate to present the contents in different formats, including the possibility of video, so that the training could be more diversified, and the contents explained more clearly and understandably. Thus, some free access LMS were analysed, which support training with video resources, in addition to the possibility of preparing tests, conducting evaluations, statistics on trainees' school results, monitoring the trainees' learning path, managing users by training, controlling the visibility of content and automatically issuing certificates after completion of training. The LMS that was chosen was the Open edX LMS ${ }^{1}$, because besides being a free system, it has some unique characteristics that distinguish it from other LMS (Ch \& Popuri, 2013): it provides several courses in various areas of education, and can be enrolled only in those that are intended to be held; the platform can be accessed anywhere and on any mobile device; it provides open forums 24/7, giving trainees a tool to discuss, interact and collaborate with each other; it provides a free digital certificate to the trainee if he has successfully completed the course, verifying and proving the authenticity of a particular course. Thus, a platform based on the Open edX technology was developed and called INTERNOVA. The target public and user of the INTERNOVA platform are the employees of companies in the agri-food industry, from the North of Portugal and Spain, associated with the INTERNOVAMARKET-FOOD project, who have heterogeneous backgrounds. Therefore, as regards training for employees of companies in the agri-food industry, in this article we refer to teacher/student as trainer/trainee. The e-learning platform was developed having interesting characteristics for the intended training, aimed at companies that are partners in the aforementioned project. This technology is a great tool for trainers and trainees. On the one hand, it facilitates the work of adding and editing media contents (texts, images, videos, among others), provide access to statistics on the completion of training and progress of trainees, evaluation of training and the consequent issue of a certificate of successful training completion. On the other hand, it allows the trainees to enrol in the desired training courses, allowing the trainee to attend a training course anywhere and at any time, according to their availability, respecting their own pace of learning. After identifying the training courses and their characteristics, as well the LMS that support it, the INTERNOVA platform was developed, initially through the design of its structure, based on the philosophy of the training courses that were intended to be made available, followed by the production of educational multimedia content.

\section{INTERNOVA PLATFORM USABILITY}

Usability can be considered by itself a methodology to support the design process, as Nielsen (2012) states "the word usability can also be referred to as a method to improve ease of use during the design process". Krug (2006) states that in a usability test, the process should take place with one user at a time. In that test, an user interface is presented to a user, e.g. a prototype of a website or an application for mobile devices, etc. and

\footnotetext{
${ }^{1}$ https://open.edx.org/
} 
questions are asked in order to find out whether that user can perform the proposed tasks. In the testing process, Krug (2006) states that the ideal number should be around three or four users, and the objectives of the test, as well the questions/tasks to be asked to the users should be established in advance. It was then decided to test the platform in order to try to validate its usability. The platform was tested by a group of four volunteers (two acting as trainees and the other two as trainers) aged between 25 and 39 years old who, after using it, answered a questionnaire in order to validate the platform from the perspective of the trainee as well as from the perspective of the trainer.

\subsection{Method}

In order to validate the platform developed, users were asked to register and interact with the platform according to their profile (trainee or trainer). The trainees were asked to perform a training. To do so, they would have to start and complete it until they obtained their certificate. The trainers were asked to create a training course with all its components (description, image and moments of evaluation). Subsequently, in order to analyse the difficulties encountered, a questionnaire was applied with a series of questions related to the experience of using the platform, both from the point of view of the trainee and the trainer, in order to evaluate the difficulty presented in solving the proposed tasks. Two questionnaires were prepared, one for trainees (having 12 questions) and the other for trainers (having 11 questions). The questions in the first questionnaire were related to the tasks possible to be carried out by the trainees and the second one questions were related to the tasks possible to be carried out by the trainers. In this way, an attempt was made to test the whole range of tasks that the platform supports. The evaluation was carried out according to a Likert scale, scored with five levels - level 1 ("Difficult") to level 5 ("Easy").

\subsection{Results Analysis}

From the analysis of the questionnaires to the trainees it was found that they evaluated 10 of the 12 tasks with level 5 (maximum positive level of the scale used). Therefore, the results obtained show that the trainees did not experience difficulties in performing the vast majority of the tasks proposed (Table 1).

Table 1

\begin{tabular}{lcc} 
Tasks & Trainee 1 & Trainee 2 \\
\hline 1. Access the studio: http://internova.ipvc.pt & 5 & 5 \\
2. Login: "aluno@ipvc.pt" psw: "testealuno" & 5 & 5 \\
3. Search all available training course & 5 & 5 \\
4. Register for the "International Featured Standards \& British Retail Consortium" training & 5 & 5 \\
course & 5 & 5 \\
5. Check which training courses you are enrolled in & 5 & 5 \\
6. See training course & 5 & 4 \\
7. Check how long you have until the end of the training course & 5 & 5 \\
8. Accessing the videos & 5 & 5 \\
9. Complete the first moment of evaluation & 5 & 5 \\
10. Conclude the second moment of evaluation & 4 & 3 \\
11. Access the "INTERNOVAMARKET-FOOD" website through the platform & 5 & 5 \\
12. Ending session & 5 \\
\hline
\end{tabular}

There was, however, a dispersion of opinions regarding two issues: verification of the time until completion of the training course and access to the "INTERNOVAMARKET-FOOD" project website. Regarding the first question, one of the trainees rated with level 4 "Check how long you have until the end of the training", which was different from the previous items that rated with level 5, while the other maintained the level 5 rating. As for the second question, one of the trainees classified as level 4 and the other as level 3. It was found that this difficulty was due to the fact that the trainee was being asked to verify information whose visibility would not be the most obvious. From the analysis of the trainers' questionnaires (Table 2), a greater divergence of opinions was observed. In 5 of the 11 questions the trainers answered, in consensus, with the maximum positive level of 5. This agreement is relative to the activities of access to the platform, creation of a training course, elimination of content and end of session. 
Table 2

Tasks

1. Access the studio: http://internova.ipvc.pt:18010

2. Login: "professor@ipvc.pt" psw: "teste2019"

3. Create a new training course

4. Upload a photo to better identify the training course

5. Edit the description of the training presentation page

6. Add two sections, each section should contain one unit

7. In the first section, in the respective unit, create a statement for a multiple-choice question, with 3 options, related to the statement

8. In the second section, on the respective unit, add a video and also a multiple-choice question related to the video

9. Publish these contents

10. Delete one of the sections created

11. Ending session

Trainer 1 Trainer 2

$\begin{array}{ll}5 & 5 \\ 5 & 5 \\ 5 & 5 \\ 1 & 2 \\ 1 & 2 \\ 3 & 5 \\ 4 & 4 \\ 4 & 5 \\ 1 & 5 \\ 5 & 5 \\ 5 & 5\end{array}$

It was found that there was a divergence of opinions on 5 tasks, with 3 of them the trainers responding with level 1 ("Difficult"). In these tasks it was proposed to upload a photo identifying the training course created, edit the description of that training course and publish content. It was found that, for achieving these objectives, the access to them was not so direct and/or intuitive, which motivated some difficulty on the part of the trainers, since for the remaining topics under analysis, the process of resolution was, for the most part, at the distance of a click and in some of them (for example: create a new training, add a section or unit) are of immediate access on the page of the training course. After some time using the platform, the trainers ended up getting acquainted with the tools and access to them, with a very fluid use. Regarding the remaining points of divergence, Trainer 1 experienced some difficulties in adding units, sections and contents to the training. Trainer 2 was able, without any problems, to perform the same proposed tasks, by assessing with the maximum positive level (5).

After the analysis of the results, it can be seen that the trainers did not experienced difficulties in performing the tasks initially proposed in the questionnaire, which leads us to conclude that the care that was taken throughout the development of the project resulted in a platform with a very good usability, intuitive and dynamic. All the tasks from the beginning of the session, through the registration, until the conclusion of the session was accomplished without any problems.

\section{CONCLUSION}

In a constantly evolving and increasingly competitive society, access to lifelong learning is urgently needed. These training courses, taking into account the target audience that is in the active life, should be in the e-learning modality. This article presents an e-learning platform - INTERNOVA, developed with support of the Open edX LMS technology, with the purpose of providing online training course to employees of companies in the agri-food industry in Northern Portugal and Galicia. In the development of the INTERNOVA platform, the target audience has always been taken into account: company employees. Thus, the platform was designed as simple and intuitive as possible, seeking to maximize the platform's usability, which was tested by trainees and trainers whose feedback from them was very positive. Additionally, it should be noted that the INTERNOVA platform can also be used in an educational context. The results obtained suggest that the platform has a potential for good usability, is intuitive and dynamic.

\section{ACKNOWLEDGMENT}

This work was supported by INTERREG V-A Espanha-Portugal (POCTEP) 2014-2020 (0437_INTERNOVAMARKET-FOOD_1_E) under the development of the project entitled "INTERNOVAMARKET-FOOD - Programa acelerador para aumentar a competitividade do sector alimentar da Galiza-Norte de Portugal". 


\section{REFERENCES}

Alheit, P. \& Dausien, B., 2006. Lifelong learning and training process. Educação e Pesquisa, Vol. 32, No 1, pp 177-197.

Balaouras, P., Gatzonis, M., Tsimpanis, K., Apostolidis, H. \& Tsiatsos, z., 2018. Towards an online video platform for MOOCs. Multimedia Tools and Applications, Vol. 77, pp.12749-12775.

Barros, D. \& Neves, C., 2017. ELearning pedagogic identification instrument for the business environment. RPGE-Revista on line de Política e Gestão Educacional, Vol. 21, № 3, pp. 1517-1549.

Ch. S. \& Popuri, S., 2013. Impact of online education: A study on online learning platforms and edX, IEEE International Conference in MOOC, Innovation and Technology in Education (MITE), pp. 366-370.

Field, J., 2000. Lifelong learning and the new educational order. Stoke on Trent, UK.

Ice, P., 2013. Advancing Platform Technologies in Online Learning. eLearning \& Software for Education. No 1, pp. 616-621.

Krug, S., 2006. Don't Make Me Think: A common sense approach to web usability. Second edition, p.135. California: New Riders.

McGill, T. \& Klobas, J., 2009. A task-technology fit view of learning management system impact. Computers \& Education, Vol 52, pp 496-508.

Moreno, J., 2015. O valor económico da informação na sociedade em rede. Observatório Journal, Centro de Investigação e Estudos de Sociologia - Instituto Universitário de Lisboa. Vol. 9, № 2, pp 001-028.

Nielsen, J., 2012. Usability 101: Introduction to Usability. Nielsen Norman Group. Retrieved in May 12, 2020. http://www.nngroup.com/articles/usability-101-introduction-to-usability.

Simões, T., Rodrigues, J. \& Torre, I., 2013. Personal Learning Environment Box (PLEBOX): A New Approach to E-Learning Platforms Computer Applications In Engineering Education, Vol. 21, No 1, pp. 100-109. 